\title{
Forced displacement: an emerging indirect impact of Covid-19 pandemic in America and the rest of the world. Prospects and Solutions
}

\author{
Dandison Nat Ebeh ( $D$ mailnat2004@yahoo.com ) \\ Central Michigan University College of Health Professions https://orcid.org/0000-0002-3555-7146 \\ Peace Chikaodili Okpala \\ University of North Carolina at Greensboro \\ Tunde M Akinmoladun \\ Central Michigan University
}

\section{Research Article}

Keywords: Forced Displacement, COVID-19, SARS-CoV-2, USA, World, Global Pandemic response, Eviction Moratorium, Narrative review

Posted Date: September 3rd, 2021

DOI: https://doi.org/10.21203/rs.3.rs-869556/v1

License: (c) (i) This work is licensed under a Creative Commons Attribution 4.0 International License. Read Full License 


\section{Abstract}

\section{Background and aims}

Despite Global efforts in the ongoing COVID-19 pandemic response, the SARS-Cov-2 virus presents a growing concern for the forced displacement of persons from their communities. People are forcibly evicted or displaced to other places by both the direct or indirect sequelae of the disease. The direct sequelae have been the movement of people from communities of high COVID-19 endemicity to areas of a perceived low COVID-19 endemicity and, or threats to life. The indirect sequelae have occurred mainly following the associated shutdown of social services (hospitals, schools, transportation, etc.), eviction from community or housing, and loss of livelihood posed by COVID19. New policy and practice approach in the Global pandemic response that incorporates timely measures to address any COVID-19 induced forced displacement and offer humanitarian assistance to individuals impacted are needed. This is also on the hill of a looming lifting and or expiration of the Centers for Disease Control and Prevention "temporary protection of housing eviction (eviction moratorium)" in the USA and elsewhere, so many individuals or families will likely be homeless and become internally displaced persons post public health emergency declaration. The present study aims to bring to the limelight this ongoing but yet to addressed complications of the COVID-19 pandemic and recommends possible solutions for this pandemic and any future disease outbreaks.

\section{Methods}

We carried out multiple online and database searched on COVID-19 induced-forced displacement of persons. Furthermore, we conducted an online search of COVID-19 induced displacement monitoring and tracking in the USA and globally, as well as that on data collected and/or compile through intergovernmental organizations (IGOs) and non-governmental organizations. In a narrative review, we try to identify COVID-19 induced forced displacement data provided online from the inception of the pandemic outbreak-December 2019 to August 2021.

\section{Results}

We included data from a biannual data report on forced displacement provided by three intergovernmental organizations as identified on their websites. Recommendations were made for incorporating active monitoring and tracking of COVID-19 induced Force displacement/evicted persons post expiration of "temporary protection from housing eviction" in the Global pandemic effort with a view to providing baseline data for intervention and targeted humanitarian assistance to displaced persons.

\section{Conclusions}

The COVID-19 pandemic continues to cause forced displacement of persons and communities, alongside attendant humanitarian needs. Incorporating COVID-19 induced forced displacement monitoring and tracking is a key solution to minimizing the collateral suffering, morbidity, and mortality associated with the ongoing COVID-19 pandemic or future disease outbreak. We also suggested the establishment of a specific center for Disease outbreak (COVID-19 pandemic) induced-forced displacement studies in America.

\section{Introduction}

Globally the covid-19 pandemic continues to wreak havoc at all levels, from the individual level to the family and even to the community (Centers for Disease Control and Prevention (CDC), 2021(a); World Health Organization (WHO), 2021(a); Nicola et al. 2020). As of today, the devastating impact of the Covid-19 pandemic cannot be 
quantified in terms of scale or value. Currently standing at a Global Death of over $4.4 \mathrm{M}$ and a total case of over 216 M and still counting (JHU, 2021; CDC, 2021(a), WHO, 2021(a); world-o-meter, 2021). The United States has been the worst hit with a total death of over 637 thousand and a total case of over 38.8 million and counting (JHU, 2021; CDC, 2021 a, WHO, 2021 a). The cost of the pandemic on any individual, family, or country has reflected on every facet and sphere of life (Calder, 2021). Nearly every intervention or public health measure to curb the menace presents hard choices for individuals, families, and communities (CDC, 2021 b, CDC, 2021 c). From lockdown measures, quarantine, to isolations, to vaccine mandates and now disaster-induced forced displacement of people due to shutdown of communities inflicted by high infectivity rates (CDC, 2021 b, CDC, 2021 c). The most recently affected community has been the Iraan community of the US state of Texas where due to over 42 percent positivity of its 1,200 residents and a record-high new case of 50 persons within 2 weeks has been forced to shut down (texas.gov). Another dimension to this been the expiration of the CDC, $2021 \mathrm{~d}$.) temporary protection from eviction recommendation and government order post public health declaration of emergencies. The associated forced migration of persons constitutes a potentially serious public health problem of another catastrophic dimension.

According to the internally displaced monitoring center (iDMC), 2021 as of 31 December 2020 there were about 126,000 internally displaced persons (IDPs) and 1714,000 newly displaced persons in America. The global total of IDPs at the same time was at 55M and 40.5M for new displacement in 2020 alone (iDMC, 2021). Furthermore, the UNHCR, (2021) added that forced displacement did surpass 80 million people as of the midyear of 2020 review with the COVID-19 pandemic presenting as a test to refugees' protection. These individuals ordinarily face an array of challenges ranging from environmental and health to socioeconomic, relatively more than a comparative nondisplaced person and now with the COVID-19 pandemic. Some of which include eviction from housing/ lack of shelter, food insecurity, safety, mental health crisis, sanitary conditions, diarrheal diseases, foodborne illness, epidemic outbreak etc. This is aside from the associated financial cost and irreparable losses suffered from COVID19. Thus, effort incorporating displaced persons humanitarian intervention measures in the ongoing COVID-19 pandemic Global response can help mitigate these seemingly envisaged emerging humanitarian challenges and it is essential to minimizing or checkmating the untoward episodic surge of the COVID-19 pandemic. This work tries to identify the occurrence of COVID-19 induced forced displacement with an aim to bring to the limelight this ongoing but less attended complication of COVID-19 pandemic and recommends possible solutions for this pandemic humanitarian disaster and future disease outbreaks. Also, to inform policy and practice in complex emergencies, post-emergency recovery, and development contexts.

\section{Methods}

We carried out a narrative review on multiple electronic online websites and databases using keywords forced displacement, COVID-19, SARS-CoV-2, USA, World, Global Pandemic response. We started with an online google search of COVID-19 town shutdown and induced displacement monitoring and tracking in the USA (local, state, and federal) and worldwide. Later we review forced displacement annual data from December 2019 to August 2021 posted on three intergovernmental organizations (IGOs)-Office of the United Nations High Commissioner for Refugees (UNHCR), International Organization for Migration (IOM), as well the non-governmental organization the Internal Displacement Monitoring Centre (iDMC). In the review, we identify recent news reports of COVID-19 induced force-displacement in the USA. Data searches were limited to a comparative of the world and USA forced displacement disasters.

\section{Results}


List of intergovernmental organizations on Force displacement and refugee Studies shown in Tables 1, 2 and 3.

\section{Discussion}

Tables 1, 2, 3 describe the lists of organizations and databases that are within the mandate and field of forced displacement of persons or communities, globally. However, it was observed in this result finding that forced displacement of persons and communities one year on, the commencement of the COVID-19 pandemic is yet to be specifically monitored, tracked, or commissioned through intergovernmental organizations, databases, or nongovernmental organizations based on likely lack of the incorporation of COVID-19 induced forced displacement. However, most organizations tailored their mandates to reflect humanitarian assistance that is worsened by the outbreak of the COVID-19 pandemic, which no doubt reflects in every facet of human existence. It is imperative that individuals or communities forcefully displaced or would be displaced (i.e. on the expiration of eviction moratorium order) be specifically monitored, tracked, and offered humanitarian assistance in order to reduce the cumulative suffering, morbidity, and mortality resulting from the COVID-19 pandemic. Thus, displacement of person either on an individual or family level as in the case of eviction moratorium or that of the community as in the case of shutdown of Iraan town in Texas USA (CDC, 2021d; texas.gov.).

\subsection{A brief review of disaster types causing forced displacement}

Disaster occurring from a natural or a man-made cause and through history has resulted in a number of displacement of people. In 2005, Hurricane Katrina struck with at least 1,800 mortalities and affected the lives of almost six million people in the United States (Britannica, 2021; Culumbia.edu, 2021). The deadliest cyclone Nargis struck the country of Myanmar killing more than 146,000 people in 2008 (Culumbia.edu, 2021). In same 2008 an earthquake did hit the Sichuan Province in China, killing at least 69,000 people and leaving more than 20,000 without a home (Culumbia.edu, 2021). The cholera epidemic which broke out in August 2008 in Zimbabwe took a protracted course and cause over 98,000 cases and nearly 5,000 deaths and that of London caused almost wipe out the entire residents of London (Culumbia.edu, 2021). Ebola (CDC, 2018) and now the COVID-19 pandemic had caused an even more "complex emergencies" disaster.

\subsection{Possible complication of COVID-19 pandemic COVID-19 Induced-Forced Displacement}

\section{on communities}

The COVID-19 pandemic presents a huge challenge to the environment and health of affected communities (Cheval et al. 2020; UNhabitat, 2021). This indirectly impacts communities as a result of the health system failures and or depleted resources following channeling of resources systems for pandemic response and or associated work and school absenteeism caused by the disease or lockdown measures (CDC, 2020, UNhabitat, 2021). Displaced populations get disproportionately affected during the pandemic, by both the disease and these indirect health effects (Columbia. Edu, 2021.b). Thus, suffering, morbidity, and mortality associated with the COVID-19 pandemic become the cumulation of all the resultant events such as aggravation of pre-existing community health burdenscancer, heart disease, etc, and attendant socioeconomic sequelae-loss of loved ones, jobs, food, and homes/evictions (CDC, 2021e). Given the below explanation.

1. Worsened infectivity as a result of the breakdown of public health effort to achieve key prevention measures

2. Worsened morbidity as a result of the shutdown of the health system 
Lockdown of communities and forced displacement of people leads to further reduction of life-saving measures with an attendant outbreak of mental illness and infectious diseases, civil unrest, food insecurity, malnutrition, socioeconomic, political, and economic upheaval (Columbia. Edu, 2021.b; CDC, 2021 a; CDC, 2021 b; UNhabitat, 2021). Fear of contagion and safety are palpable concerns that lead to further displacement even among the displacement population (Iraklis G. 2020; Columbia. Edu, 2021.b ; CDC, 2021 a; CDC, 2021 b). Traditional caregiving structures may be disrupted by displacement and control measures impacting caregivers. It is difficult to maintain continuity of care chronic health conditions, including HIV and TB, in contexts of displacement; this may be exacerbated during the pandemic response (Iraklis G. 2020; Columbia. Edu, 2021.b ; CDC, 2021 a; CDC, 2021 b). Food shortages, that impact on these humanitarian settings increases the risk of acute malnutrition amongst displaced individuals.

\subsection{COVID-19 Induced-Forced Displacement most impacted population}

Forced displaced usually disproportionately impact on the most vulnerable population in the community. This includes persons with specific needs especially people at extreme age in the community, and individuals with disabilities, immunosuppressed or chronic disease (Iraklis G. 2020; Columbia. Edu, 2021.b ; CDC, 2021 a; CDC, 2021

b). This is in a context that they face unique challenges in the face of a doubling of exacerbation of preexisting conditions and COVID-19 infection risks. WHO estimates that 15\% of the world's population has a disability (WHO, 2020). Displaced persons living with disabilities, including mobility restrictions, frequently rely on public transport to access essential services, including health care and food distribution points which will be absent during displacement from their communities (WHO, 2020; Iraklis G. 2020; Columbia. Edu, 2021.b).

According to UNHCR, (2021), older refugees comprises of $8.5 \%$ of the overall population of the vulnerable groups. Older persons have an increased risk of death or severe COVID-19 disease, due to their age. They also frequently have mobility restrictions and other health conditions that place them at additional risk of health complications if their treatment is interrupted (Iraklis G. 2020; Columbia. Edu, 2021.b ; CDC, 2021 a; CDC, 2021 b). Many older displaced people who rely on social support networks to meet their basic needs are finding that assistance has been reduced or withdrawn during the pandemic (Iraklis G. 2020; Columbia. Edu, 2021.b ; CDC, 2021 a; CDC, 2021 b). Social isolation resulting from social distancing and lockdown measures may also place older people at greater risk of psychosocial distress and mental, physical and cognitive decline (Iraklis G. 2020; Columbia. Edu, 2021.b ; CDC, 2021 a; CDC, 2021 b)..

Another set of people that require specific needs are women and children (Iraklis G. 2020; Columbia. Edu, 2021.b ; CDC, 2021 a; CDC, 2021 b). The COVID-19 crisis has contributed to an "exponential increase" in on women and children globally, attributed to an increase in socio-economic stressors associated with the pandemic, social isolation, food insecurity, measures and mobility restrictions that may increase exposure to family violence, and reduced access to support services (Iraklis G. 2020; Columbia. Edu, 2021.b ; CDC, 2021 a; CDC, 2021 b ; UN, 2021). Services to prevent and respond to gender base violence and family violence should be considered essential services, and efforts made to adapt them in accordance with COVID-19 prevention measures (Iraklis G. 2020; Columbia. Edu, 2021.b ; CDC, 2021 a; CDC, 2021 b; UN, 2021).

\subsection{Impact of COVID-19 pandemic on displaced population.}

Prior to the onset of the COVID-19 pandemic along with its complex and compounding effect persecution and conflict had caused forced displacement of over 80 million from their homes in 2020 (UNHCR, 2021). Displaced persons fall into the most vulnerable and marginalized members of the society and constitute higher group following limited 
access to clean water, sanitation and health care centers (UNHCR, 2021). COVID-19 Global pandemic response disproportionately impact forcibly displaced persons because they mostly have lost livelihood and are most part in poverty (UNHCR, 2021). In fact, over 80 percent of them resides in low to middle income countries or underserved in developed nations. Integrating this groups into pandemic response and keeping them safe present an advantage in controlling the spread and recurrence of disease outbreaks (UNHCR, 2021).

\subsection{Pragmatic solutions}

Pragmatic solutions will entail the below recommendations and should ideally cut across relevant stake holders of the community and this will include women, youths, religious groups, traditional institutions, civil society organizations, employers of labor, educational institutions, government (federal, state, local and tribal).

\subsection{Recommendations}

1. A long-term and sustainable delivery of essential health services and public pandemic response measures is vital to reducing additional deaths, illnesses, and or suffering due to the COVID-19 pandemic.

2. The COVID-19 response must integrate the voices, needs, and priorities of displaced populations, with particular attention to the marginalized and at-risk populations-especially the poor, IDPs/refugees/migrants, women and children and persons with disability or chronic illnesses.

3. All interventions should be harmless, with specific attention to contextual needs, challenges, and possible unintended consequences like homelessness due to community shutdown or individual/family housing eviction.

4. Extension of the Centers for Disease Control and Prevention "temporary protection of housing eviction (eviction moratorium)" through the public health emergencies and increase resources for housing and properties owners.

5. Consider all context and avoid a "one size fits all" approach. Lockdowns are often implemented with the assumption that everyone have access to social services, safe drinking water, adequate sanitation, communication, electricity, and sufficient food and income. In humanitarian contexts, these requirements are usually so or not met. It is important to ensure that individuals and communities can continue to meet basic needs, through the provision of financial assistance, food, and other support.

6. Early COVID-19 induced-displacement monitoring and tracking both at local, state, federal levels, including for evicted individuals and families. Also, data on forced migration should be collected and/or compile through various intergovernmental organizations (IGOs), such as the office of the United Nations High Commissioner for refugees (UNHCR), (UNHCR), the Internal Displacement Monitoring Centre (iDMC), International Organization for Migration (IOM), as well as non-governmental organizations (NGOs), such as the international Displacement Monitoring Centre (iDMC). So as to inform humanitarian policies and practice in this complex emergency-preintra-post pandemic situation.

7. Provision of sheltering service for the displaced persons through NGOs like the American Red cross.

8. Establishment of the center for Disease outbreaks induced Forced displacement studies in Universities or research institutes.

9. Immediate Establishment of Internally Displaced persons (IDPs) camp, isolation, or quarantine center across all countries to cater for humanitarian needs of persons displaced by the COVID-19 pandemic and are affected by direct or indirect sequelae (loss of housing, livelihood, socio service). Especially on expiration of Eviction moratorium. 


\subsection{Limitation of Study}

This is a quick work to stir up humanitarian policy and practice on COVID-19 induced forced displacement in America and around the world, as such it may be limited in coverage, search strategy, scope, data acquisition, and analytics thus it is expected that further research should improve on these shortcomings. Also, any error in this work is unintentional, and however regrettable where any, thus constructive criticism and contribution are most welcome.

\section{Conclusions}

Early integration of forced displacement monitoring, tracking, and humanitarian intervention into the COVID-19 pandemic Global response by policy and practice are crucial to early prevention of further forced displacement of persons, episodic disease outbreak, and a resultant collapse of the health system from the raging COVID-19 pandemic. This present study brought to the limelight this ongoing but unattended complication of the COVID-19 pandemic and recommended possible solutions to inform further research, policy, and practice in complex emergencies pre, during, and post-pandemic.

\section{Declarations}

Compliance with Ethical Standards

Disclosure of potential conflicts of interest

We declare no conflicts of interest

Ethic approval

Not applicable

Informed Consent

Not applicable

Consent for Publication

DNE conceptualized the idea, authors consent to publication

Funding

No funding was received for conducting this study.

\section{Contributions}

DNE conceptualized the study and wrote the manuscript under the supervision of TMA. PO contributed in execution of study under the supervision of SE. All authors contributed in online search and proof reading of manuscript prior to submission.

Acknowledgments 
DNE acknowledge that this work arose from academic research carried out at Central Michigan University, USA. The authors express their gratitude to the Central Michigan University department of public health, the University of North Carolina at Greensboro Department of Public health education, and the authors of cited references. Acknowledgment also to Sandra E. Echeverria Ph.D. of the University of North Carolina at Greensboro for her useful contribution.

Code availability

Not applicable

Data availability

Not applicable

\section{References}

1. Britannica T, Editor of Encyclopaedia (Invalid Date). Hurricane Katrina. Encyclopedia Britannica. https://www.britannica.com/event/Hurricane-Katrina.

2. Calder R, Grady C, Jeuland M, Kirchhoff CJ, Hale RL, Muenich RL. COVID-19 Reveals Vulnerabilities of the FoodEnergy-Water Nexus to Viral Pandemics. Environ Sci Technol Lett. 2021;8(8):606-15. https://doi.org/10.1021/acs.estlett.1c00291.

3. CDC. 2021a. COVID-19 Data tracker available from.

4. https://covid.cdc.gov/covid-data-tracker/\#trends_dailycases 8/29/2021.

5. CDC. 2021b. Reducing the stigma. Available from https://www.cdc.gov/mentalhealth/stress-coping/reducestigma/index.html.08/21/2021.

6. CDC. 2021 c. Available from https://www.cdc.gov/coronavirus/2019-ncov/community/schools-childcare/k-12guidance.html\# 8/29/2021.

7. CDC,2021d. Temporary protection from eviction. Available from https://www.cdc.gov/coronavirus/2019ncov/covid-eviction-declaration.html. 8/30/2021.

8. CDC,2021d. COVID-19 available from.

9. https:// 8/3021.

10. CDC. 2020. Emerging infectious disease. Available from https://wwwnc.cdc.gov/eid/article/26/8/201093_article 8/30/2021.

11. CDC. 2018. Bushment. Available from https://www.cdc.gov/importation/bushmeat.html.

12. Cheval S, Mihai Adamescu C, Georgiadis T, Herrnegger M, Piticar A, Legates DR. Observed and Potential Impacts of the COVID-19 Pandemic on the Environment. Int J Environ Res Public Health. 2020;17(11):4140. https://doi.org/10.3390/ijerph17114140.

13. Columbia. Edu(2021a). Forced migration Learning module. Available from.

14. http://www.columbia.edu/itc/hs/pubhealth/modules/forcedMigration/definitions.html 08/29/2021.

15. Columbia. Edu (2021.b). Forced migration Learning module. Available from.

16. https://.

17. iDMC. (2021); Available from https://www.internal-displacement.org/ 08/30/2021.

18. IOM. (2021). data-and-research. Available from https://www.iom.int/data-and-research 08/29/2021. 
19. Iraklis G. Facing Forced Displacement: Overcoming Adverse Childhood Experiences. Journal of child adolescent trauma. 2020;14(2):261-9. https://doi.org/10.1007/s40653-020-00320-2.

20. Mucherera B, Spiegel S. (2021). Forced displacement: critical lessons in the protracted aftermath of a flood disaster. GeoJournal, 1-21. Advance online publication. https://doi.org/10.1007/s10708-021-10471-w.

21. Laborde D, Martin W, Swinnen J, Vos R. COVID-19 risks to global food security. Science. 2020;369(6503):500-2. https://doi.org/10.1126/science.abc4765.

22. Northwestern libraries. (2021). Forced migration and refugee studies. Available from.

23. https://libguides.northwestern.edu/c.php?g=115119\&p=749119 08/30/2021.

24. Nicola M, Alsafi Z, Sohrabi C, Kerwan A, Al-Jabir A, losifidis C, Agha M, Agha R. The socio-economic implications of the coronavirus pandemic (COVID-19): A review. International journal of surgery (London England).

2020;78:185-93. https://doi.org/10.1016/j.ijsu.2020.04.018.

25. Texas.gov. (2021). Available from https://www.dshs.texas.gov/news/updates.shtm 08/27/2021.

26. http://www.columbia.edu/itc/hs/pubhealth/modules/forcedMigration/definitions.html.

27. JHU. 2021. Available from https:// coronavirus.jhu.edu/map.html 8/28/2021.

28. World-o-meter. 2021. Coronavirus. Available from.

29. https://www.worldometers.info/coronavirus/ 9/28/2021.

30. https://.

31. Northwestern libraries. (2021). Forced migration and refugee studies. Available from.

32. https://libguides.northwestern.edu/c.php?g=115119\&p=749119 08/30/2021.

33. UN. 2021. pandemic-violence-against-women-and-girls.

34. Available from https://www.un.org/en/addressing-impact-covid-19-pandemic-violence-against-women-and-girls 08/30/2021.

35. UNhabitat. 2021. Available from.

36. https://unhabitat.org/sites/default/files/2021/03/cities_and_pandemicstowards_a_more_just_green_and_healthy_future_un-habitat_2021.pdf 08/30/2021.

37. UNHCR. (2021). Available from.

38. https:// 08/29/2021.

39. WHO. 2020. Disability and Health. Available from https://www.who.int/news-room/fact-sheets/detail/disabilityand-health 08/30/2021.

\section{Tables}

Table 1 List and brief description of Intergovernmental organization and websites 
Organization

Mandates

Website

Centre for

Refugee

Studies-York

University

The center engages in research on refugee issues and informs public discussion, policy creation and practice. It also supports teaching in migration and refugee studies, as well as connecting across service organizations, governmental, and international organizations.

European

Council on

Refugees \&

Exiles(ECRE)
The ECRE mandate is on the needs of all individuals who seek protection and refuge within Europe. http://www.yorku.ca/crs

https://ecre.org/

http://www.refugeelegalaidinformation.org/

Fahamu

Refugee

Programme

Promotes the legal protection of refugees around the globe by centralizing resources for refugees and legal assistance providers..

\section{Internal}

Displacement

Monitoring

Centre

(iDMC)

International

Organization

for Migration

(IOM)

Refugee

Research

Network
The iDMC contributes to the improvement of national and international capacities to protect and assist displaced persons around the world who had been displaced within their own country as a result of human rights violations or conflicts

The IOM offers reports, research, results, publications, maps, and lots more on human trafficking, resettlement, labor migration and related issues. http://www.internal-displacement.org/

http://www.iom.int/

knowledge among practitioners, scholars, and policy makers to benefit people who have been forcibly displaced. The goal for which is to build a network of networks which will promote connections throughout the field of refugee and forced migration studies.

Refugee Studies Centre (RSC) Oxford
The Refugee Studies Centre was founded in 1982 as part of the Oxford Department of International Development (Queen Elizabeth House) at the University of Oxford. Its purpose is to build knowledge and understanding of the causes and effects of forced migration in order to help improve the lives of some of the world's most vulnerable people.

\section{U.S.} Committee for Refugees and Immigrants (USCRI)

\section{UN Refugee} Agency (UNHCR)
The main purpose of the (USCRI) is to serve displaced people, without discrimination by nationality, race, ideology, or social group. They also serve victims of human trafficking and protect the rights of unaccompanied immigrant children.

The agency was established on December 14, 1950 by the United Nations General Assembly. Their main focus is to lead an international action to protect refugees and resolve refugee problems globally.

\section{Refugee}

Processing

Center-

The Refugee Processing Center is controlled by the U.S Department of State (DOS) Bureau of Population, Refugees, and Migration (PRM). http://www.rsc.ox.ac.uk/

http://www.refugees.org/

http://www.unhcr.org/

http://www.wrapsnet.org/admissions-andarrivals/

Admissions 
and Arrivals

International The ICRC is an international organization

Committee of focused on aiding people affected by conflict

https://www.icrc.org/en

the Red

Cross (ICRC) and armed violence and ensuring the protection of victims by law.

Source: Northwestern libraries, (2021)

\section{Table 2}

List of intergovernmental organization databases on forced displacement and refugee Studies 
Directories Comments Website

and

Databases

Organization

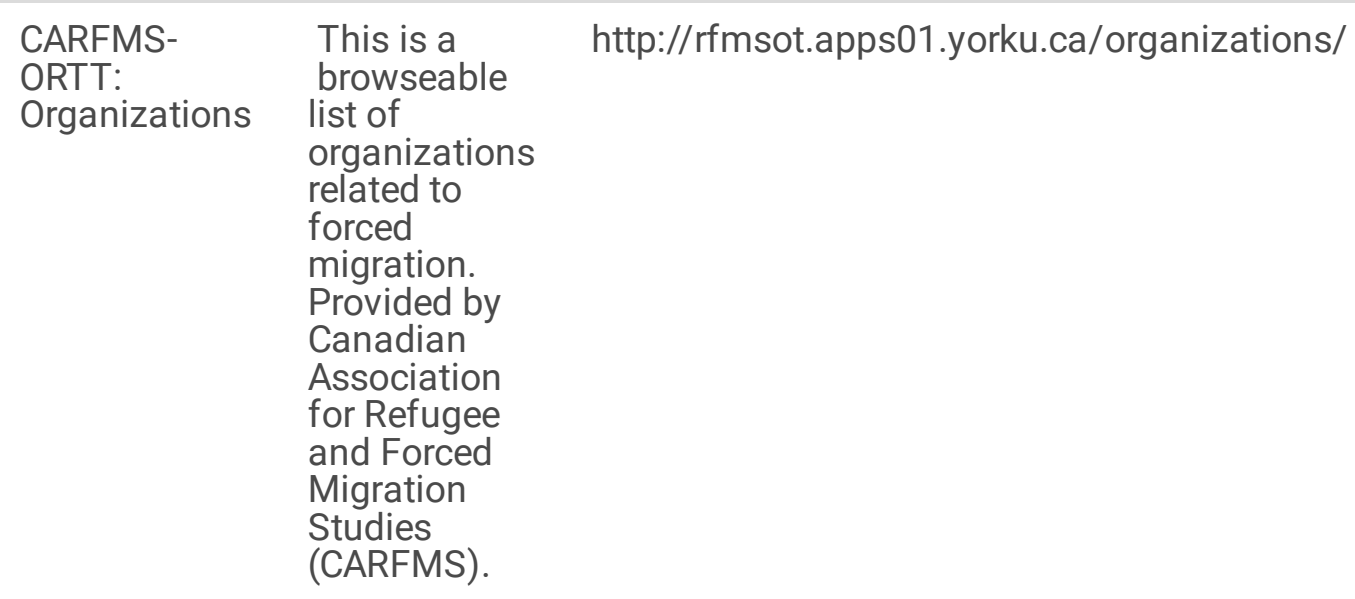

Duke

University

NGO

Database
This is both a searchable list and browsable database of

Nongovernmental organization websites. http://library.duke.edu/research/subject/guides/ngo_guide/ngo_database.html ht/library.duke.edu/research/subject/guides/ngo_guide/ngo_database.html 
Table 3. Global Forced Displacement 2020 Summary

Agency

United Nations High Commissioner for refugees (UNHCR)

\begin{tabular}{ll} 
& 80 million people forcefully displaced \\
\hline Internal displacement Monitoring Centre (iDMC) & 55.0 million- Total 2020 Global displacement \\
& 40.5 million-Global 2020 New displacement
\end{tabular}

126,000-Total 2020 US displacement

1,714,000-US 2020 New displacement

International Organization for Migration (IOM)

281 Million, International Migrant in 2020

$3.6 \%$ of Global population

Source: iDMC, (2021); IOM, (2021); UNHCR, 2021 